\title{
Do Girls Really Experience More Anxiety in Mathematics?
}

Psychological Science 24(10) 2079-2087

(C) The Author(s) 2013

Reprints and permissions:

sagepub.com/journalsPermissions.nav DOI: $10.1177 / 0956797613486989$ pss.sagepub.com

\author{
Thomas Goetz ${ }^{1,2}$, Madeleine Bieg ${ }^{1,2}$, Oliver Lüdtke ${ }^{3}$, \\ Reinhard Pekrun ${ }^{4}$, and Nathan C. Hall ${ }^{5}$ \\ ${ }^{1}$ Department of Empirical Educational Research, University of Konstanz, ${ }^{2}$ Thurgau University of Teacher \\ Education, ${ }^{3}$ Institute of Psychology, Humboldt University Berlin, ${ }^{4}$ Department of Psychology, \\ University of Munich, and ${ }^{5}$ Department of Educational and Counselling Psychology, McGill University
}

\begin{abstract}
Two studies were conducted to examine gender differences in trait (habitual) versus state (momentary) mathematics anxiety in a sample of students (Study 1: $N=584$; Study 2: $N=111$ ). For trait math anxiety, the findings of both studies replicated previous research showing that female students report higher levels of anxiety than do male students. However, no gender differences were observed for state anxiety, as assessed using experience-sampling methods while students took a math test (Study 1) and attended math classes (Study 2). The discrepant findings for trait versus state math anxiety were partly accounted for by students' beliefs about their competence in mathematics, with female students reporting lower perceived competence than male students despite having the same average grades in math. Implications for educational practices and the assessment of anxiety are discussed.
\end{abstract}

\section{Keywords}

emotions, sex differences, science education, academic achievement, mathematics achievement

Received 9/24/12; Revision accepted 3/22/13

Female students report higher levels of mathematics anxiety than do male students, as documented in meta-analyses of studies with secondary-school students from around the globe (Hyde, Fennema, Ryan, Frost, \& Hopp, 1990; see also Else-Quest, Hyde, \& Linn, 2010, for data from the Programme for International Student Assessment, PISA; Organisation for Economic Co-operation and Development, 2004). These findings are discouraging, given the negative effects of anxiety on psychological health, learning behaviors, self-regulation, and academic achievement (Diener, 2000; Pekrun, Goetz, Titz, \& Perry, 2002; Zeidner, 1998). Research has further shown that math anxiety negatively predicts course enrollment, career choices, and lifelong learning in mathematicsrelated fields, thus contributing to the underrepresentation of females in many domains of science, technology, engineering, and mathematics (STEM; Eccles, 2012; Halpern et al., 2007; National Academy of Sciences, 2006; Wigfield, Battle, Keller, \& Eccles, 2002; Wirtz, Kruger, Napa Scollon, \& Diener, 2003). This gender gap in math anxiety stands in marked contrast to the fact that female students typically obtain similar, or only slightly lower, levels of achievement in mathematics relative to their male counterparts (Else-Quest et al., 2010; Hyde, Lindberg, Linn, Ellis, \& Williams, 2008).

However, existing research on mathematics anxiety is almost exclusively based on self-reports of traitlike (habitual) anxiety, as opposed to state (momentary) anxiety assessed during real-life experiences. Given that trait and state self-report assessments can lead to very different results (e.g., Porter et al., 2000), this notable omission of state-based measures raises the issue of whether differences in math anxiety actually exist between male and female students in everyday life. By evaluating both traitand state-based measures of math anxiety in students of various ages, we aimed in the present study to directly address this intriguing question.

\section{Corresponding Author:}

Thomas Goetz, University of Konstanz, Universitätsstraße 10, 78457

Konstanz, Germany

E-mail: thomas.goetz@uni-konstanz.de 


\section{The Gender Gap in Math Anxiety: The Issue of Perceived Competence}

There is considerable empirical support for the idea that self-report measures of trait anxiety are significantly impacted by subjective beliefs (Robinson \& Clore, 2002). In contrast, such beliefs are much less likely to bias realtime reports of anxiety experienced in a given situation (state anxiety). This assumption is in line with the accessibility model of emotional self-reports (Robinson \& Clore, 2002), in which state measures are assumed to evaluate emotions, whereas trait measures better reflect beliefs about emotions.

Subjective beliefs involving personal competence (hereafter referred to as competence beliefs) represent a critical antecedent of anxiety and play a central role in self-reports of trait emotions more generally (Pekrun, 2006). Research has shown that, compared with boys, girls typically report significantly lower levels of perceived competence on measures of math-related self-efficacy and perceived ability (Goetz, Frenzel, Hall, \& Pekrun, 2008; Hyde et al., 1990). Given the relative lack of differences between boys and girls in mathematics achievement, findings further suggest that gender stereotypes about mathematics may be largely responsible for girls' lower levels of perceived competence in this domain, as evidenced by statements like "Girls and mathematics are a bad fit" or "Mathematics is clearly a male domain" (Keller, 2002; Steele \& Aronson, 1995; see also mathematics-related stereotypes within the internal/ external frame-of-reference model; Marsh, 1986).

Given these findings, we propose that the gender gap in trait mathematics anxiety may be due to the use of trait self-report methods that allow personal-competence beliefs to bias reports of anxiety. Moreover, we propose that measures of anxiety completed by students while they are actually learning about math or being tested on math content should be less impacted by the students' personal beliefs and show weaker gender differences than trait measures. Although girls may report more trait math anxiety than boys because of lower levels of perceived competence, such gender differences should be less pronounced on self-report measures of state math anxiety. This assertion is consistent with results from a few prior studies showing gender differences on trait, but not state, selfreport measures of related variables (e.g., coping strategies: Porter et al., 2000). However, to the best of our knowledge, no empirical studies have yet explored this research question with respect to math anxiety.

\section{The Present Research}

In the present research, we evaluated the assertion that girls report higher levels of anxiety in mathematics on trait-oriented self-report measures than do boys, but that this gender difference is less pronounced in state selfreports. By implication, we expected girls to show a greater discrepancy than boys in their levels of trait and state math anxiety (Hypothesis 1). We further expected that the greater discrepancy in reported trait and state math anxiety for girls could be explained by girls' lower competence beliefs, given the importance of such appraisals as antecedents of self-reported trait emotions (Hypothesis 2). Although not the primary focus of the present study, it was further anticipated that our findings would replicate previous research showing girls and boys to have similar grades in mathematics.

Two studies were conducted, each of which evaluated both trait and state self-report measures of anxiety, selfreports of perceived competence, and math achievement. To evaluate the generalizability of the study findings, we assessed both test-related and class-related math anxiety and included students of various age groups in the study samples. In Study 1 (5th to 10th graders), test anxiety in mathematics was assessed using both trait and state measures, with the latter completed during a math test. In Study 2 (8th and 11th graders), class-related mathematics anxiety was assessed using trait and state measures, with the latter administered during regular math classes. In both studies, the state measures of anxiety involved experience-sampling methods (Csikszentmihalyi \& Larson, 1987; Hektner, Schmidt, \& Csikszentmihalyi, 2007).

\section{Method}

\section{Samples and procedure}

The samples consisted of students from multiple grade levels in the top track of the education system in Germany (i.e., Gymnasium; approximately one third of the total student cohort). The Study 1 sample consisted of 584 students (from 24 classes at six schools) from Grades 5 through 10 (45\% female, $55 \%$ male; mean age $=13.67$ years, $S D=1.84)$. This study was part of the Project for the Analysis of Learning and Achievement in Mathematics (Pekrun et al., 2007). The Study 2 sample consisted of 111 students (2 to 4 students randomly selected from each of 41 classrooms across seven schools) from Grades 8 and 11 (53\% female, $47 \%$ male; mean age $=15.96$ years, $S D=1.71)$.

In both studies, trait and demographic data were assessed using a standardized questionnaire at the beginning of the study, after which state self-report measures were administered. In Study 1, state mathematics test anxiety was assessed immediately prior to a mathematics test and twice during the test (after approximately one third and two thirds of the test had been completed). The self-report questions were integrated into the answer 
sheet for the test. In Study 2, state class-related mathematics anxiety was assessed via a digital questionnaire presented on a personal digital assistant (PDA) following a randomized audible signal. The signal sounded once during each math class over a 2-week period. Students activated the PDA at the start of each class, and the signal sounded at randomized times over the next $40 \mathrm{~min}$ (five assessments per student on average).

\section{Study measures}

Anxiety. In Study 1, trait mathematics test anxiety was assessed using the Achievement Emotions QuestionnaireMathematics (see Pekrun, Goetz, Frenzel, Barchfeld, \& Perry, 2011). Participants were instructed to rate how they typically felt when taking tests in mathematics (four items, e.g., "When taking the math test, I am tense and nervous"; $\alpha=.83$ ). State mathematics test anxiety was assessed with the item "I am anxious" (see Goetz, Preckel, Pekrun, \& Hall, 2007). The answer format for the trait and state measures was a 5-point Likert scale ranging from 1, strongly disagree, to 5, strongly agree. In Study 2, trait and state mathematics anxiety were assessed with the following items: "How much anxiety do you generally experience during mathematics classes?" (trait anxiety) and "How much anxiety are you experiencing during this class?" (state anxiety). Responses for both items were made using 5-point Likert-type scales from 1, not at all, to 5 , very strongly.

Perceived competence. Subjective perceptions of competence were operationalized as self-efficacy and selfconcept beliefs (cf. Skinner, 1996) and assessed using established scales. In Study 1, trait mathematics self-efficacy was measured with a four-item scale used in PISA assessments (Organisation for Economic Co-operation and Development, 2003, 2004; sample item: "I am confident that I can understand even the most difficult content in mathematics"; $\alpha=.89$ ). Responses were made using 5-point Likert-type scales from 1, almost never, to 5, almost always. In Study 2, academic self-concept was assessed using three items of the Self-Description Questionnaire (Marsh, 1990; German version, Kunter et al., 2002; sample item: "Mathematics is one of my best subjects"; $\alpha=.89$ ). Responses were made using 5-point Likert scales ranging from 1, strongly disagree, to 5, strongly agree.

Achievement. In both studies, academic performance was operationalized as students' midterm grades in mathematics, which, in the German school system, are typically based on scores for a single written exam combined with scores for course-specific oral exams. Grades range from 1, very good, to 6, insufficient, with higher numbers representing poorer performance. To interpret achievement values more intuitively, we inverted grade values so that higher numbers indicated better performance.

\section{Data analysis}

To evaluate the main study hypotheses, we adopted a multilevel, intraindividual modeling approach to account for the nested structure of the data in both studies. For each of the two studies, Hierarchical Linear Modeling software (Version 6.08; Raudenbush, Bryk, \& Congdon, 2007) was used to conduct multilevel analyses comprising three levels (measures nested within students, and students nested within classrooms).

Level 1 (measures within students). Students' anxiety scores served as the outcome variable and included two types of measures within each person-namely, one trait measure (Study 1: trait-anxiety score divided by the number of items; Study 2: the score on the single traitanxiety item) and multiple state measures (Study 1: three ratings-one before and two during the test; Study 2: experience-sampling assessments during class-four ratings per participant, on average). The trait/state variable (uncentered) differentiated between the type of measure used ( $0=$ state, $1=$ trait). Because of the coding of this variable, the intercept evaluated as $\gamma_{000}$ describes overall mean state anxiety when other linear terms' coding values also are 0 (e.g., mean state anxiety for males, mean state anxiety for students with average levels of self-rated competence). This variable's effect $\left(\gamma_{100}\right)$ can be interpreted as the difference between trait and state anxiety scores, with positive values indicating that trait scores were higher than state scores.

Level 2 (student level). Two Level 2 variables and their interaction term were included in our models, namely gender $\left(0=\right.$ male, $1=$ female; $\gamma_{010}$, uncentered $)$, competence (Study 1: self-efficacy; Study 2: self-concept; $\gamma_{020}, z$ scores standardized across persons), and Gender $\times$ Competence $\left(\gamma_{030}\right.$, multiplicative term).

Level 3 (class level). The classes in which students were nested constituted the third level. The class level was included to take into account the clustering of students within classes when estimating standard errors.

Cross-level interactions Level 1-Level 2. Three crosslevel multiplicative interaction terms were included in our models, namely Trait/State $\times$ Gender $\left(\gamma_{110}\right)$, Trait/State $\times$ Competence $\left(\gamma_{120}\right)$, and Trait/State $\times$ Gender $\times$ Competence $\left(\gamma_{130}\right)$. These interaction terms represented the effects 
of gender, competence, and the Gender $\times$ Competence interaction on the difference between trait- and state-anxiety scores.

A number of different models were calculated to test the study hypotheses, each of which was constructed as a slopes-as-outcome model (Raudenbush \& Bryk, 2002). ${ }^{1}$ Model 1 examined the effect of the Trait/State $\times$ Gender interaction $\left(\gamma_{110}\right)$, thus testing if gender was a predictor of the effect of the trait/state variable. As such, Model 1 assessed whether the discrepancy between trait- and state-anxiety scores differed between boys and girls (Hypothesis 1). Model 2 examined the effect of the Trait/ State $\times$ Competence interaction $\left(\gamma_{120}\right)$, thus testing if competence was a predictor of the discrepancy between traitand state-anxiety scores. In Model 3, both gender and competence were included as predictors of the trait-state discrepancy $\left(\gamma_{110}, \gamma_{120}\right)$. As such, Model 3 tested if gender effects on the trait-state discrepancy were reduced when competence was included, and thus examined competence as a mediator of gender effects. Model 4 additionally included the three-way interaction of the trait/state variable, gender, and competence $\left(\gamma_{130}\right)$, thus testing if the effects of competence differed by gender. In all of the models, the corresponding main effects were also included $\left(\gamma_{010}, \gamma_{020}, \gamma_{030}\right)$. Constructing our models in this manner allowed us to infer whether gender differences in the discrepancy between trait and state math anxiety can be explained by gender-linked differences in competence beliefs (Hypothesis 2).

\section{Results}

\section{Preliminary analyses}

Table 1 provides the results of $t$ tests for boys and girls on the key study variables, as well as corresponding effect sizes (Cohen's $d s$; Cohen, 1988), for both studies (also see Fig. 1). The pattern of results was as anticipated: In both studies, girls reported significantly higher trait anxiety and lower competence beliefs than did boys. The size of these effects was medium to large. However, girls and boys did not significantly differ with respect to mathematics achievement or state anxiety (concerning math tests in Study 1 and math class in Study 2). ${ }^{2}$ In Study 1, separate analyses for each of the three single state-test-anxiety items also revealed no significant gender differences.

\section{Main analyses}

The results of the main analyses are outlined in Table 2 .

Model 1. The main effect of the type of measure (trait/ state variable; $\gamma_{100}$ ) on the anxiety scores was significant for Study 1 but not for Study $2 .^{3}$ The main effect of gender on the anxiety scores $\left(\gamma_{010}\right)$ was not significant in either study. By contrast, the effect of the Trait/State $x$ Gender interaction $\left(\gamma_{110}\right)$ was significant in both studies (Study 1: .47; Study 2: .77). This finding strongly supports Hypothesis 1 in showing that gender predicted differences between self-reported trait and state math anxiety,

Table 1. Descriptive Statistics, Mean-Level Differences, and Related Effect Sizes for Key Study Variables

\begin{tabular}{|c|c|c|c|c|c|c|}
\hline \multirow[b]{2}{*}{ Measure and study } & \multicolumn{2}{|c|}{ Boys } & \multicolumn{2}{|c|}{ Girls } & \multirow[b]{2}{*}{$t$} & \multirow[b]{2}{*}{ Cohen's $d$} \\
\hline & $M$ & $S D$ & $M$ & $S D$ & & \\
\hline \multicolumn{7}{|l|}{ Trait Anxiety } \\
\hline Study 1 & 2.63 & 1.02 & 3.11 & 1.12 & $t(572)=-5.40 * * *$ & -0.32 \\
\hline Study 2 & 1.62 & 1.05 & 2.39 & 1.35 & $t(109)=-3.39 * * * *$ & -0.45 \\
\hline \multicolumn{7}{|l|}{ State Anxiety } \\
\hline Study 1 & 1.35 & 0.58 & 1.34 & 0.53 & $t(570)=0.27$ & 0.01 \\
\hline Study 2 & 1.55 & 0.80 & 1.48 & 0.61 & $t(109)=0.50$ & 0.07 \\
\hline \multicolumn{7}{|l|}{ Competence } \\
\hline Study 1 & 2.95 & 0.73 & 2.48 & 0.82 & $t(552)=7.04^{* * * * *}$ & 0.43 \\
\hline Study 2 & 3.29 & 1.19 & 2.53 & 1.10 & $t(109)=3.52^{* * *}$ & 0.47 \\
\hline \multicolumn{7}{|l|}{ Achievement } \\
\hline Study 1 & 4.22 & 0.94 & 4.14 & 1.01 & $t(571)=1.03$ & 0.06 \\
\hline Study 2 & 3.98 & 1.09 & 3.76 & 0.97 & $t(108)=1.11$ & 0.15 \\
\hline
\end{tabular}

Note: Positive $t$ values reflect higher scores for boys than for girls. For multi-item measures, scale values were divided by the number of items. Subjects in Study 1 were 316 boys and 268 girls; subjects in Study 2 were 52 boys and 59 girls.

**k $p<.01 .{ }^{* * * * *} p<.001$. 

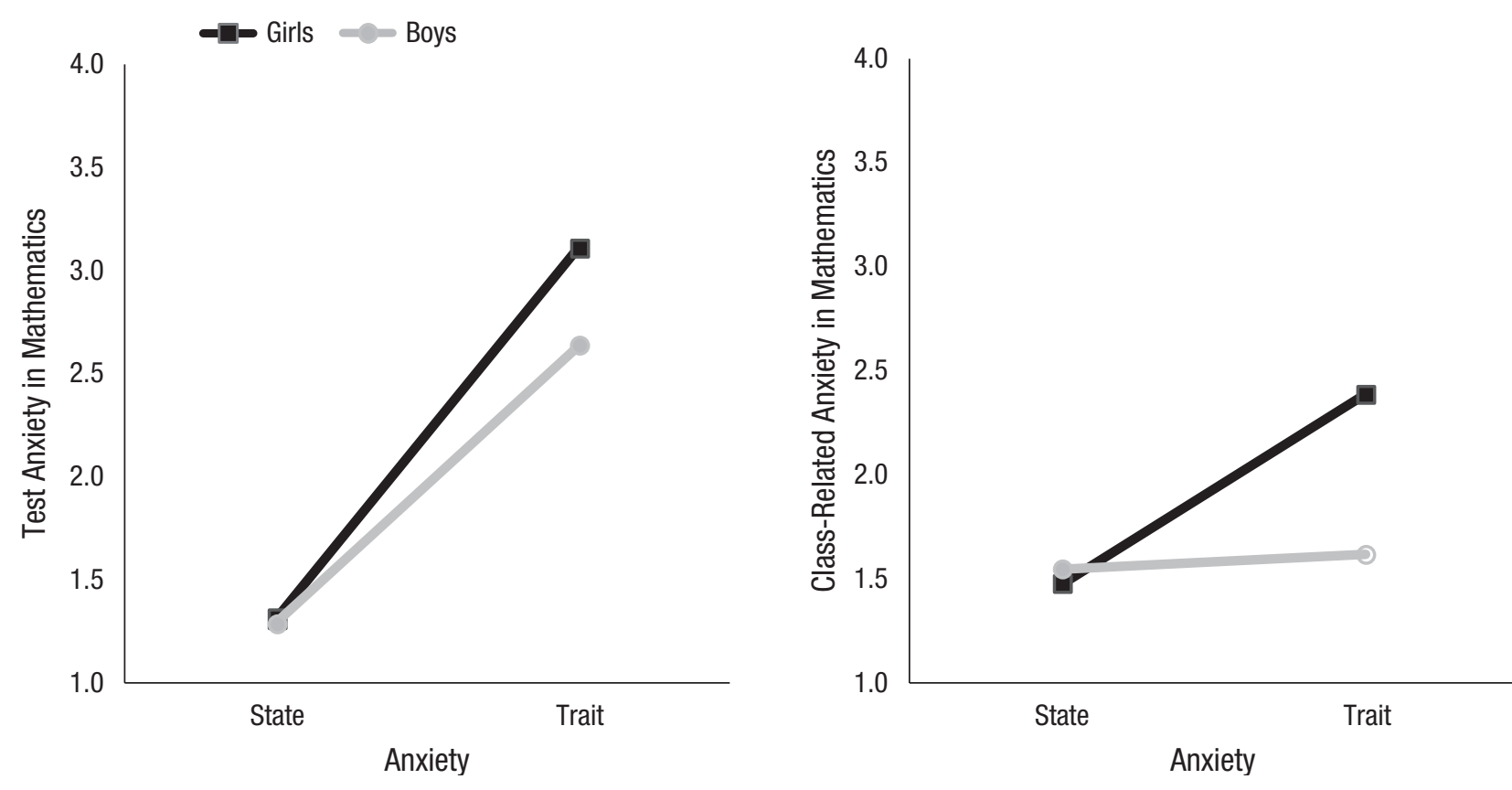

Fig. 1. Results of Studies 1 and 2. The graph on the left shows mean levels of test anxiety in mathematics as a function of trait/state anxiety and gender (Study 1). The graph on the right shows mean levels of class-related anxiety in mathematics as a function of trait/ state anxiety and gender (Study 2).

with the discrepancy being significantly greater for girls than for boys.

Model 2. The effect of the Trait/State $\times$ Competence interaction $\left(\gamma_{120}\right)$ was significantly negative in both studies (Study 1: -.55 ; Study 2: -.37 ). This effect showed that higher competence beliefs corresponded with notably weaker trait-state differences in anxiety.

Model 3. The effect of the Trait/State $\times$ Competence interaction $\left(\gamma_{120}\right)$ continued to be significant in both studies. The effect of the Trait/State $\times$ Gender interaction $\left(\gamma_{110}\right)$ was significant in Study 2 but no longer significant in Study 1. As compared with the effect revealed by Model 1, this effect of gender on the trait-state discrepancy was reduced in both studies because of the inclusion of the Trait/State $\times$ Competence interaction term (Study 1: .47-.18; Study 2: .77-.61).

Model 4. Findings revealed that the effects of gender on the trait-state discrepancy $\left(\gamma_{110}\right)$ and competence on the trait-state discrepancy $\left(\gamma_{120}\right)$ were additive, as $\gamma_{130}$ did not reach statistical significance in either study.

In Models 1 through 4, the effect of gender on the trait-state discrepancy $\left(\gamma_{110}\right)$ can be interpreted as a moderator effect: Gender played a significant role in predicting how large the differences between trait and state anxiety were. The findings further suggest that this moderating effect of gender $\left(\gamma_{110}\right)$ was partly mediated by perceived competence, given the reduction seen for the Trait/State $\times$ Gender coefficient $\left(\gamma_{110}\right)$ when the Trait/ State $\times$ Competence interaction was added $\left(\gamma_{120}\right)$. The pattern here is of mediated moderation (Preacher, Rucker, \& Hayes, 2007). Thus, the results support Hypothesis 2 by showing that girls' trait-state discrepancies were associated with their lower levels of perceived competence relative to boys' levels. ${ }^{4}$

\section{Discussion and Conclusion}

The present findings are consistent with findings from previous research documenting the well-known gender gap in self-reported trait mathematics anxiety, but they expand upon previous results in showing that girls reported higher levels of anxiety than boys on trait self-reports but not on state-based measures. Put simply, these findings suggest that girls do not, in fact, experience more anxiety than boys do during mathematics instruction and testing situations, despite reporting higher levels of habitual math anxiety. Moreover, the study findings indicate that girls' competence beliefs, which were lower than those of boys despite girls' and boys' similar achievement outcomes, may be partly responsible for girls' higher levels of reported habitual mathematics anxiety. 


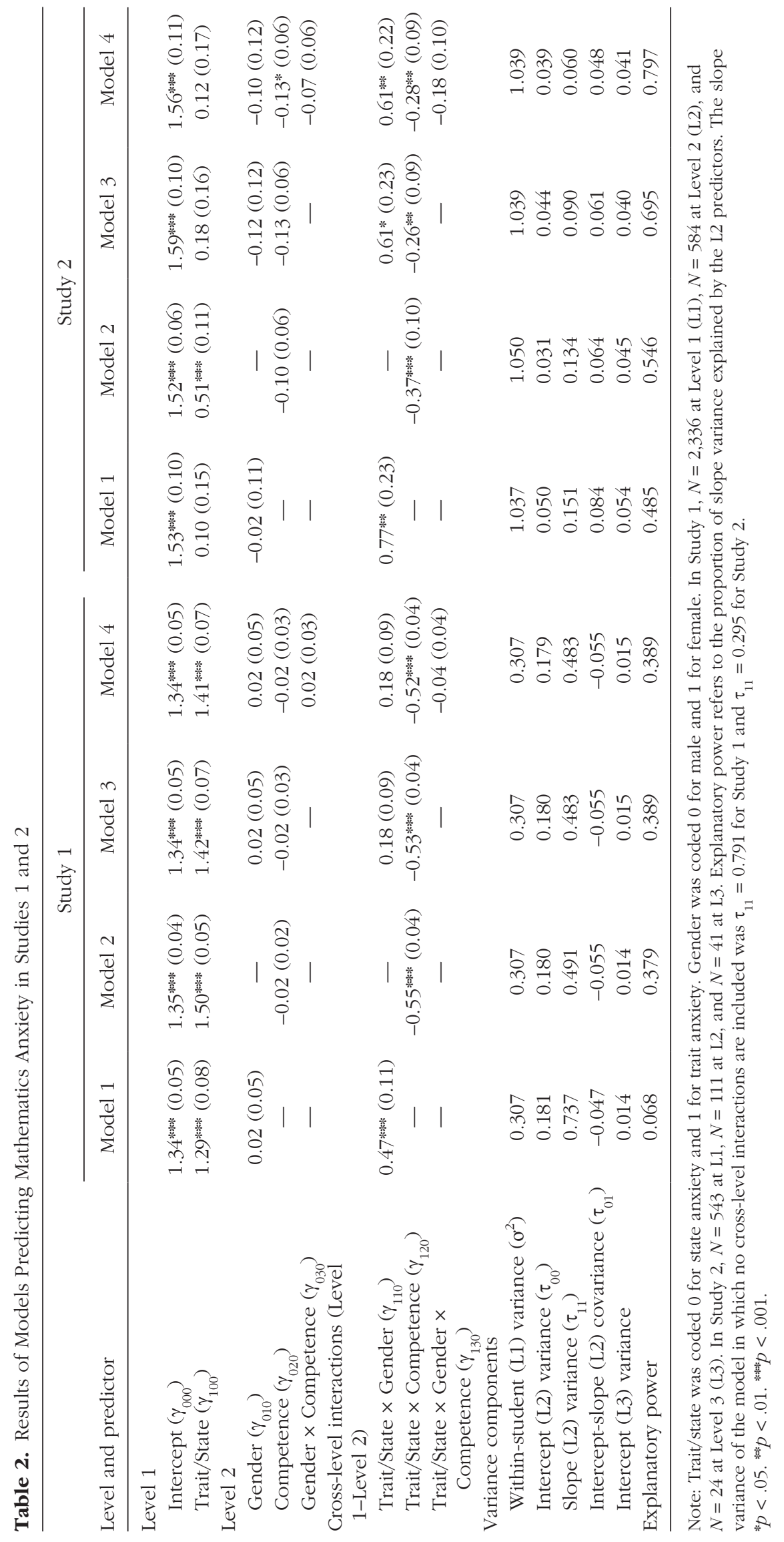


The present finding that trait-oriented self-reports of anxiety are impacted by competence beliefs is in line with the accessibility model of emotional self-reports (Robinson \& Clore, 2002), in which state measures are understood to evaluate individuals' emotions (i.e., actual experiences), whereas trait measures are understood to reflect individuals' beliefs about emotions. Competence judgments represent perhaps the most critical cognitive appraisal with respect to students' emotions, as reflected by their observed power $37.9 \%$ and $54.6 \%$ in Studies 1 and 2, respectively) for explaining the discrepancy in levels of trait versus state math anxiety. However, other mathematics-related cognitions also warrant investigation in this regard (e.g., perceived value, content difficulty, achievement expectations; Pekrun, 2006) to further elucidate the specific cognitive processes responsible for gender differences on self-reports of trait anxiety. Moreover, research on the role of gender stereotypes about mathematics as potential antecedents of the gender bias in these anxiety-arousing cognitions would also be an intriguing area for future investigation (cf. Keller, 2002; Wheeler \& Petty, 2001).

In a comparison of trait and state self-reports (Study 2 allows for such a comparison because of the use of parallel item wordings), our findings suggest that girls do indeed tend to overestimate their habitual mathematics anxiety, whereas boys do not. Our results also confirm that competence beliefs play an important role in girls' overestimation of trait math anxiety (cf. research on the intensity bias in trait vs. state measures; Buehler \& McFarland, 2001). The assertion that reflective cognitive processes may be responsible for gender differences in self-reported trait math anxiety is further supported by the lack of gender differences in math achievement, which suggests that psychological constructs, over and above performance, merit attention as antecedent variables.

From a practical perspective, the fact that the effect of gender on self-reported perceived trait math anxiety may largely be due to stereotyped cognitions (as opposed to ability) is troubling, considering the negative impact of perceived trait anxiety on subjective well-being, motivation, and learning behavior. Given that self-reports of trait mathematics anxiety have also been empirically linked to decision-making processes (cf. Wirtz et al., 2003), it is possible that girls' unfounded beliefs about their math anxiety contribute to the underrepresentation of females in math-intensive domains such as the physical sciences, technology, and engineering.

To reiterate, our findings suggest that whereas girls report greater habitual anxiety in mathematics than do boys, they do not, in fact, experience greater anxiety than boys when learning about or being tested on math content. Our study samples consisted of students from the highest track of the German school system, a large proportion of whom are high achievers and are expected to assume positions of leadership in society. Thus, even among these high achievers, a sizeable number of female students can be expected to not pursue further study or employment in math-intensive domains (Eccles, 2012) simply because of lower subjective evaluations of their math abilities and, consequently, higher levels of perceived habitual math anxiety relative to boys.

Although these findings depict a troubling scenario in which girls may opt out of entire occupational domains because of unjustified biases and perceived anxiety levels, they are also encouraging in suggesting that this situation can be improved by directly addressing girls' self-defeating cognitions and emotions in mathematics. Educators could help girls improve their well-being and engagement in math-related domains by explicitly informing them that their achievement and anxiety in actual math classes do not significantly differ from those of the boys, despite persistent beliefs to the contrary. Similarly, cognitive interventions (e.g., Hall et al., 2007) could be used to reduce the gender gap in trait math anxiety. Such measures can be expected to have farreaching economic implications by potentially increasing returns on societal investments in STEM education and redressing the present international shortage of experts in math-intensive fields (e.g., engineers, scientists). By encouraging girls to not shortchange their potential for success in these domains, the gender gap in perceptions of math anxiety, and the detrimental consequences of girls' beliefs that they experience more anxiety than they actually do, may be substantially reduced.

\section{Author Contributions}

All authors contributed to the study design. All authors approved the final version of the manuscript for submission.

\section{Declaration of Conflicting Interests}

The authors declared that they had no conflicts of interest with respect to their authorship or the publication of this article.

\section{Funding}

This research was supported by grants from the German Research Foundation to R. Pekrun (Project for the Analysis of Learning and Achievement in Mathematics Grants PE 320/11-1, PE 320/11-2, PE 320/11-3, and PE 320/11-4).

\section{Supplemental Material}

Additional supporting information may be found at http://pss sagepub.com/content/by/supplemental-data

\section{Notes}

1. The mixed equation for Model 4 was as follows: Anxiety ${ }_{i j k}=$ $\gamma_{000}+\gamma_{010} \times$ Gender $+\gamma_{020} \times$ Competence $+\gamma_{030} \times$ Gender $\times$ 
Competence $+\gamma_{100} \times$ Trait/State $+\gamma_{110} \times$ Trait/State $\times$ Gender + $\gamma_{120} \times$ Trait/State $\times$ Competence $+\gamma_{130} \times$ Trait/State $\times$ Gender $\times$ Competence $+r_{0 j k}+r_{1 j k} \times$ Trait/State $+u_{00 k}+e_{i j k}$. The indices $i$, $j$, and $k$ refer to measures, persons, and classrooms, respectively. 2. Pearson product-moment correlations were used to evaluate the relations among math anxiety, perceived competence, and math achievement. Trait math anxiety correlated negatively with math achievement in Study 1 (boys: $r=-.35, p<.01$; girls: $r=-.42, p<.01$ ) and Study 2 (boys: $r=-.15$, n.s.; girls: $r=-.27$, $p<.05)$. Trait math anxiety also correlated negatively with competence beliefs in Study 1 (boys: $r=-.46, p<.01$; girls: $r=-.51$, $p<.01$ ) and Study 2 (boys: $r=-.12$, n.s.; girls: $r=-.44, p<.01$ ). Correlations between state math anxiety and math achievement were not significant. Finally, there was a significant positive correlation between competence beliefs and math achievement in Study 1 (boys: $r=.43, p<.01$; girls; $r=.50, p<.01$ ) and Study 2 (boys: $r=.78, p<.01$; girls: $.78, p<.01$ ). These links between trait math anxiety and math achievement and between competence beliefs and math achievement are in line with findings from numerous previous studies (e.g., Goetz, Frenzel, Pekrun, Hall, \& Lüdtke, 2007; Ma, 1999; Valentine, DuBois, \& Cooper, 2004), supporting the validity of our study measures.

3. Scores for trait and state anxiety could be directly compared in Study 2 because of parallel item wordings. They could not be directly compared in Study 1 because of the use of different measures in the trait and state assessments (multiitem scale vs. single item). In other words, in Study 1, the main effect for the trait/state variable confounds the trait-versus-state framing with item wording. However, this confound does not inherently imperil this variable's interactions (e.g., with gender), which are more central to the study's aims.

4. In supplementary analyses, we included academic achievement and grade level (Study 1: Grades 5, 6, and 7 vs. Grades 8, 9, and 10; Study 2: Grade 8 vs. Grade 11) as additional predictors in all four models. Controlling for achievement and grade level in this way led to a pattern of results that was equivalent to the findings of the main analyses and left the conclusions of the studies unaffected. Results of these analyses are available online in the Supplemental Material.

\section{References}

Buehler, R., \& McFarland, C. (2001). Intensity bias in affective forecasting: The role of temporal focus. Personality and Social Psychology Bulletin, 27, 1480-1493. doi:10.1177/ 01461672012711009

Cohen, J. (1988). Statistical power analysis for the behavioural sciences (2nd ed.). Hillsdale, NJ: Erlbaum.

Csikszentmihalyi, M., \& Larson, R. (1987). Validity and reliability of the Experience-Sampling Method. Journal of Nervous and Mental Diseases, 9, 526-536.

Diener, E. (2000). Subjective well-being. American Psychologist, $55,34-43$.

Eccles, J. (2012, April). Expectancy-value theory and gendered academic and occupational choices. Paper presented at the 2012 annual meeting of the American Educational Research Association, Vancouver, British Columbia, Canada.

Else-Quest, N. M., Hyde, J. S., \& Linn, M. C. (2010). Crossnational patterns of gender differences in mathematics: A meta-analysis. Psychological Bulletin, 136, 103-127.
Goetz, T., Frenzel, A. C., Hall, N. C., \& Pekrun, R. (2008). Antecedents of academic emotions: Testing the internal/ external frame of reference model for academic enjoyment. Contemporary Educational Psychology, 33, 9-33.

Goetz, T., Frenzel, C. A., Pekrun, R., Hall, N. C., \& Lüdtke, O. (2007). Between- and within-domain relations of students academic emotions. Journal of Educational Psychology, 99, $715-733$.

Goetz, T., Preckel, F., Pekrun, R., \& Hall, N. C. (2007). Emotional experiences during test taking: Does cognitive ability make a difference? Learning and Individual Differences, 17, 316.

Hall, N. C., Perry, R. P., Goetz, T., Ruthig, J. C., Stupnisky, R. H., \& Newall, N. E. (2007). Attributional retraining and elaborative learning: Improving academic development through writing-based interventions. Learning and Individual Differences, 17, 280-290.

Halpern, D. F., Benbow, C. P., Geary, D. C., Gur, R., Hyde, J. S., \& Gernsbacher, M. A. (2007). The science of sex differences in science and mathematics. Psychological Science in the Public Interest, 8, 1-51.

Hektner, J. M., Schmidt, J. A., \& Csikszentmihalyi, M. (2007). Experience Sampling Method: Measuring the quality of everyday life. Thousand Oaks, CA: Sage.

Hyde, J. S., Fennema, E., Ryan, M., Frost, L. A., \& Hopp, C. (1990). Gender comparisons of mathematics attitudes and affect: A meta-analysis. Psychology of Women Quarterly, 14, 299-324.

Hyde, J. S., Lindberg, S. M., Linn, M. C., Ellis, A., \& Williams, C. (2008). Gender similarities characterize math performance. Science, 321, 494-495.

Keller, J. (2002). Blatant stereotype threat and women's math performance: Self-handicapping as a strategic means to cope with obtrusive negative performance expectations. Sex Roles, 47, 193-198.

Kunter, M., Schümer, G., Artelt, C., Baumert, J., Klieme, E., Neubrand, M., . . . Weiß, M. (2002). PISA 2000: Dokumentation der Erhebungsinstrumente [PISA 2000: Documentation of Scales]. Berlin, Germany: Heenemann $\mathrm{GmbH}$.

Ma, X. (1999). A meta-analysis of the relationship between anxiety toward mathematics and achievement in mathematics. Journal for Research in Mathematics Education, 30, 520540.

Marsh, H. W. (1986). Verbal and math self-concepts: An internal/ external frame of reference model. American Educational Research Journal, 23, 129-149.

Marsh, H. W. (1990). Self-Description Questionnaire (SDQ) II: A theoretical and empirical basis for the measurement of multiple dimensions of adolescent self-concept: An interim test manual and a research monograph. Macarthur, New South Wales, Australia: University of Western Sydney.

National Academy of Sciences. (2006). Beyond bias and barriers: Fulfilling the potential of women in academic science and engineering. Washington, DC: National Academies Press.

Organisation for Economic Co-operation and Development. (2003). The PISA 2003 assessment framework. Paris, France: Author. 
Organisation for Economic Co-operation and Development. (2004). Learning for tomorrow's world: First results from PISA 2003. Paris, France: Author.

Pekrun, R. (2006). The control-value theory of achievement emotions: Assumptions, corollaries, and implications for educational research and practice. Educational Psychology Review, 18, 315-341.

Pekrun, R., Goetz, T., Frenzel, A. C., Barchfeld, P., \& Perry, R. P. (2011). Measuring emotions in students' learning and performance: The Achievement Emotions Questionnaire (AEQ). Contemporary Educational Psychology, 36, 36-48.

Pekrun, R., Goetz, T., Titz, W., \& Perry, R. P. (2002). Academic emotions in students' self-regulated learning and achievement: A program of qualitative and quantitative research. Educational Psychologist, 37, 91-105.

Pekrun, R., vom Hofe, R., Blum, W., Frenzel, A. C., Goetz, T., \& Wartha, S. (2007). Development of mathematical competencies in adolescence: The PALMA longitudinal study. In M. Prenzel (Ed.), Studies on the educational quality of schools: The final report of the DFG Priority Programme (pp. 17-37). Münster, Germany: Waxmann.

Porter, L. S., Marco, C. A., Schwartz, J. E., Neale, J. M., Shiffman, S., \& Stone, A. A. (2000). Gender differences in coping: A comparison of trait and momentary assessments. Journal of Social \& Clinical Psychology, 19, 480-498.

Preacher, K. J., Rucker, D. D., \& Hayes, A. F. (2007). Addressing moderated mediation hypotheses: Theory, methods, and prescriptions. Multivariate Behavioral Research, 42, 185-227.

Raudenbush, S. W., \& Bryk, A. S. (2002). Hierarchical linear models: Applications and data analysis methods (2nd ed.). Thousand Oaks, CA: Sage.
Raudenbush, S. W., Bryk, A. S., \& Congdon, R. (2007). HLM 6.08: Hierarchical linear and nonlinear modeling. Lincolnwood, IL: Scientific Software International.

Robinson, M. D., \& Clore, G. L. (2002). Belief and feeling: Evidence for an accessibility model of emotional self-report. Psychological Bulletin, 128, 934-960. doi:10.1037/00332909.128.6.934

Skinner, E. A. (1996). A guide to constructs of control. Journal of Personality and Social Psychology, 71, 549-570.

Steele, C., \& Aronson, J. (1995). Stereotype threat and the intellectual test performance of African Americans. Journal of Personality and Social Psychology, 69, 797-811.

Valentine, J. C., DuBois, D. L., \& Cooper, H. (2004). The relation between self-beliefs and academic achievement: A metaanalytic review. Educational Psychologist, 39, 111-133.

Wheeler, S. C., \& Petty, R. E. (2001). The effects of stereotype activation on behavior: A review of possible mechanisms. Psychological Bulletin, 127, 797-826. doi:10.1037/00332909.127.6.797

Wigfield, A., Battle, A., Keller, L. B., \& Eccles, J. S. (2002). Sex differences in motivation, self-concept, career aspiration, and career choice: Implications for cognitive development. In A. McGillicuddy-De Lisi \& R. De Lisi (Eds.), Biology, society, and behavior: The development of sex differences in cognition (pp. 93-124). Westport, CT: Ablex.

Wirtz, D., Kruger, J., Napa Scollon, C., \& Diener, E. (2003). What to do on spring break? The role of predicted, on-line, and remembered experience in future choice. Psychological Science, 14, 520-524. doi:10.1111/1467-9280.03455

Zeidner, M. (1998). Test anxiety: The state of the art. New York, NY: Plenum Press. 